\title{
Culture, threat, and error: lessons from aviation
}

Robert L. Helmreich PhD FrAEs, * Jan M. Davies MSc MD FRCPC $†$

A

LTHOUGH different modes of transport, such as aviation and rail, have become increasingly safer over the past 20 years, accidents still occur. ${ }^{1}$ Similarly, adverse outcomes occur in healthcare, despite numerous improvements in areas such as, for example, selection and training of personnel, design and maintenance of equipment, and greater availability and reduced side effects of many drugs. ${ }^{2}$ However, the proportional gains in aviation have been larger than those in healthcare, and, if for this reason alone, the Institute of Medicine Report, 'To Err is Human,'3 recommended that medicine adopt aviation's approaches to safety and error management. ${ }^{4}$

\section{Similarities between aviation and healthcare}

There are similarities in the on-going struggle for safety in both healthcare and aviation. First, although safety is the primary goal, cost drives decisions. Second, both domains have, in part, become safer because of technological innovation. Third, there are multiple sources of threats to safety in both systems - technological, human, and environmental. Fourth, disasters are always followed by furious bouts of second-guessing. Fifth, teamwork is essential in reducing, trapping and mitigating or treating errors. ${ }^{5-7}$

This last point demands further elaboration. Most endeavors in healthcare, science, and industry require groups to work together effectively - this is the essence of teamwork. Failures of teamwork in complex organizations can have deadly effects. More than twothirds of air crashes involve human or pilot error as a primary factor, in contrast to the decreasing number of crashes related to primary mechanical failure. When human error is cited as a major contributor in an air crash, this occurs most often in the form of failures in teamwork, in such areas as communication and shared mental models. ${ }^{8}$

Historically, however, professional training has focused on technical, rather than on interpersonal, skills. Aviation has mandated that the flight and cabin crews work together as a team, through the use of standard operating procedures (SOPs) and formal training in teamwork and communication. In contrast, it is said that getting the diverse groups in healthcare, such as surgeons, anesthesiologists, and nurses, to work as a team is like herding cats.

Also of importance is the concept of 'context' or the 'whole situation relevant to a particular event' and its influence on team performance and error management. Four particular characteristics need to be considered: individual knowledge and skill, team composition, organizational characteristics, and culture. The last of these, culture, is often little understood, yet it is of vital importance for safety and for effective performance. Because culture has been implicated in accidents and incidents in aviation and medicine, further elaboration is required.

\section{Culture}

Culture represents the values, beliefs, and behaviours that are shared by members of groups. Culture binds us together as a group and provides the cues and clues as to how we should behave in both normal and novel situations. Culture also has multiple consequences. It influences how juniors relate to their seniors. This may be seen in those who have an unwillingness to speak up vs those who are assertive. Culture influences how information is shared, as in the use of direct $v$ sindirect speech. Culture influences adherence to rules and attitudes about stress and personal capabilities. Finally, culture also influences how humans interact with computers and technology - such as whether or not they believe the monitor or the patient. ${ }^{6}$

There are three major types of intersecting cultures. First, national culture represents the shared components of nationality, including norms, attitudes, and values, for example, the Canadian 'peace, order and good government' $v s$ the American 'life, liberty and the pursuit of happiness.' Second, professional culture defines the norms, attitudes, values and practices associated with being a pilot, doctor or nurse, for example,

From the Human Factors Research Project, The University of Texas at Austin, Austin, Texas, USA, ${ }^{*}$ and the Department of Anesthesia, The University of Calgary, Calgary, Alberta, Canada. $\dagger$

Address correspondence to: Dr. Robert L. Helmreich, University of Texas Human Factors Research Project, Department of Psychology, The University of Texas at Austin, 1 University Station A8000, Austin, Texas 78712-0187, USA. Phone: 512-475-7913; Fax: 512-4757935; E-mail: helmreich@mail.utexas.edu; Web site: www.psy.utexas.edu/HumanFactors 
carrying a stethoscope with a cloth cover (usually a nurse) or without (usually a doctor). Third, organizational culture defines the norms, attitudes, values, and practices of an airline or hospital, such as 'naming, blaming and shaming' workers after a catastrophe. ${ }^{6}$

\section{National culture}

One component of national culture is 'power distance' or PD. In high PD cultures, juniors do not question superiors. Leaders may be autocratic. Another aspect is uncertainty avoidance or UA. Groups with high UA values believe that rules should not be broken. ${ }^{9}$ One aviation study showed agreement that the organization's rules should not be broken ranging from $28 \%$ to $78 \%$ across different cultures. ${ }^{6}$ High UA groups also believe that written procedures are needed for all situations. ${ }^{9}$ Here the range of values was wider, with agreement that written procedures were needed for all in-flight situations ranging from $19 \%$ in one culture to $85 \%$ in another. $^{6}$

\section{Organizational culture}

An organization's culture reflects its values regarding error, blame, and punishment. These values relate to the openness of communications between management and workers (such as pilots). From this follows the level of adherence to regulations, the level of commitment to safety, and the level of trust between pilots and management. ${ }^{6}$

An example of the importance of organizational culture comes from the investigation of air crashes. Studies have shown that flawed organizational culture was a precursor of disaster, as demonstrated by lack of safety concerns, operational pressures, poor leadership, conflict with management, and negative organizational climate. ${ }^{1,10}$

\section{Professional culture}

Pilots and doctors have stalwart and similar professional cultures, with positive and negative aspects. The positive aspects are a shared, strong motivation to do well and great pride in each profession. The negative aspects are training that stresses the need for perfection and a deep perception of personal invulnerability and resistance to human failings such as fatigue.

In our studies at The University of Texas, we have found the majority of pilots and doctors in all cultures agree that:

- their decision-making is as good in emergencies as in normal situations;

- their performance is not affected by personal problems;

- they do not make more errors under high stress; and

- true professionals can leave behind personal problems.

There are other threats to safety in medical culture. These include suppressing discussion of medical errors, tolerance of detrimental behaviours (such as illegible handwriting and nurse-physician conflict), variability of practice standards, and widespread individual variation in medical procedures.

One threat to safety that is too well tolerated and even venerated in healthcare is that of fatigue. Professor Drew Dawson, of the University of South Australia, clearly demonstrated the similarity between sleep deprivation and alcohol intoxication on psychomotor performance. Seventeen hours of sleep deprivation have the performance effects equivalent to a blood alcohol content of $0.05 \%$ (the legal limit in all states in Australia). By the time an individual has been awake for $24 \mathrm{hr}$, the sleep deprivation has the performance effects comparable to a blood alcohol content of $0.1 \% .{ }^{11}$ In contrast, commercial aviation's flight duty limits are set at eight hours in one day, $30 \mathrm{hr}$ in one week, $100 \mathrm{hr}$ in one month, and 1,000 hr per year. In contrast, American hospital resident work rules as of July, 2003 define work limits of $24 \mathrm{hr}$ in one shift, $80 \mathrm{hr}$ in one week (with the ability to work beyond these limits), and no limits for total work time in any month or in a year. The performance decrement from sleep deprivation is a major contributor to the making of errors, which we next consider.

\section{Error}

Error is inevitable because of human limitations. These include: limited memory capacity, limited mental processing capacity, negative effects of stress, tunnel vision, and the negative influence of physiological factors such as fatigue, hunger and thirst. In both aviation and medicine, in an attempt to compensate for the imperfect human, technology has been seen as a way of reducing error. Yet technology itself is a source of threat and error. New technology does not eliminate error, nor does even newer technology. Most problems occur at the interface between teams, such as between surgeon and anesthesiologist and nurse and doctor - a rather 'untechnological' concept.

\section{Observable team errors may be classified into five basic types}

- Task execution - an unintentional physical act that deviates from the intended course of action, for example, not turning the ventilator on, after induction of anesthesia of an unstable patient in the trauma room; 
- Procedural - an unintentional failure to follow mandated procedures, such as a nurse incorrectly counting the number of sponges before the laparotomy in the trauma room;

- Communication - a failure to transmit infor mation, failure to understand information, or failure to share a mental model, such as thinking that the surgeon said 'five minutes' ( $v s$ ' 55 min');

- Decision - a choice of action unbounded by procedures that unnecessarily increase hazard, such as anesthetizing an unstable patient in the trauma room; and

- Intentional noncompliance - violations of for mal procedures or regulations, such as leaving an anesthetized patient in the trauma room to get more blood from the fridge in the recovery room.

Rather than trying to 'prevent' all errors - an impossible task in itself, ${ }^{12}$ teams and individuals are encouraged to manage errors, through reducing the frequency at which they occur, trapping the errors as they are made, and mitigating or treating the consequences of the errors and other contributing factors ${ }^{5-7}$ One systematic approach to error management is The University of Texas threat and error management model (UT-TEMM). ${ }^{6}$ This provides a template for analysis of both superior and flawed performance. The model is helpful as a conceptual framework for formal training in threat and error management. UTTEMM has also been used in analysis of air crashes, adverse events and close calls. Some of these investigations have shown that organizations with a 'good safety record' have certain characteristics, which together define the organization's safety culture.

\section{What organizations can do to build a safety culture}

First, an organization needs to define a clear policy regarding human error. Errors should be accepted and not punished, in contrast to intentional non-compliance, which should not be tolerated.

Second, formal procedures should be initiated where appropriate. SOPs were aviation's first countermeasures against threat and error. Aviation is arguably over-proceduralized, through a concept known as 'tombstone regulation.' In contrast, medicine is under-proceduralized. Although checklists are critical error countermeasures, they are sometimes regarded as being "for the lame and the weak."

Third, the dangers in fatigue should be recognized (see above). Fourth, reporting systems should be used to uncover threats and sources of error. Fifth, adverse outcomes as well as close calls (near miss/adverse/sen- tinel events) should be analyzed, using a systematic method, such as the UT-TEMM. In addition, analysis should be carried out of both the positive and negative aspects of close calls and accidents.

Sixth, formal training should be provided in threat and error management, with programs such as crew resource management (CRM) adapted to medicine and based on local data. ${ }^{13,14}$ Training topics in CRM should include human limitations as sources of error; the nature of error and error management; culture and communications; expert decision-making; training in using specific behaviours and procedures as countermeasures against threat and error. Examples of these countermeasures are briefings, inquiry, sharing mental models, conflict resolution, and fatigue and alertness management.

Organizations that implement these measures should see a decrease in a wide variety of safety-related problems, although not to the 'zero defect' level. The quest for safety in healthcare and aviation is ongoing - we will never be 'safe' but we can continue to improve.

\section{References}

1 Helmreich RL, Merritt AC. Culture at Work in Aviation and Medicine: National, Organizational, and Professional Influences. Aldershot, UK: Avebury Aviation, Ashgate Publishing Limited; 1998.

2 Davies JM, Lange IR. Investigating adverse outcomes in obstetrics. J Obstet Gynaecol Can 2003; 25 : 505-15.

3 Kobn LT, Corrigan JM, Donaldson MS. To Err is Human: Building a Safer Health System. Washington, DC: National Academy Press; 2000.

4 Helmreich $R L$. On error management: lessons from aviation. BMJ 2000; 320: 781-5.

5 Helmreich RL. Managing human error in aviation. Sci Am 1997; 276: 62-7.

6 Helmreich RL, Wilhelm JA, Klinect JR, Merritt AC. Culture, error, and crew resource management. In: Salas E, Bowers CA, Edens E (Eds). Improving Teamwork in Organizations. Applications of Resource Management Training. Mahwah, New Jersey: Lawrence Erlbaum Associates Inc; 2001.

7 Davies JM, Lange IR. Human error and its management. J Soc Obstet Gynaecol Can 2000; 22: 383-92.

8 Boeing Commercial Aircraft. Statistical summary of commercial jet aircraft accidents: Worldwide Operations $1959-2002$.

9 Hofstede G. Cultures and Organizations. Software of the Mind. Intercultural Cooperation and its Importance for Survival. London: McGraw-Hill International (UK) Limited; 1991. 
10 Maurino DE, Reason J, Johnston N, Lee RB. Beyond Aviation Human Factors. Aldershot, UK: Avebury Aviation, Ashgate Publishing Limited; 1995.

11 Dawson D, Reid K. Fatigue, alcohol and performance impairment. Nature 1997; 388: 235.

12 Davies JM, Hoffman C, Hebert P. The Canadian Patient Safety Dictionary. Ottawa, Canada: The Royal College of Physicians and Surgeons of Canada, 2003 (www.rcpsc.medical.org).

13 Davies JM, Helmreich RL. Simulation: it's a start. Can J Anaesth 1996; 43: 425-9.

14 Davies JM. Medical applications of crew resource management. In: Salas E, Bowers CA, Edens E (Eds).

Improving Teamwork in Organizations: Applications of Resource Management Training. Mahwah, New Jersey: Lawrence Erlbaum Associates, Inc.; 2001. 